\title{
Metabolic Rate and Respiratory Quotient in Birds: Results at Different Seasons, and Comparison of Two Methods
}

\author{
Valery M Gavrilov* and Vadim V Gavrilov \\ Department of Vertebrate Zoology and Zvenigorod Biological Station, M.V. Lomonosov Moscow State University, Moscow, \\ Russia
}

*Corresponding author: Valery M Gavrilov, Department of Vertebrate Zoology and Zvenigorod Biological Station, M.V. Lomonosov Moscow State University, Moscow 119991, Russia, E-mail: vmgavrilov@mail.ru

\section{ARTICLE INFO}

Received: 慧 February 04, 2021

Published: 豐 February 10, 2021

Citation: Valery M Gavrilov, Vadim V Gavrilov. Metabolic Rate and Respiratory Quotient in Birds: Results at Different Seasons, and Comparison of Two Methods. Biomed J Sci \& Tech Res 33(5)-2021. BJSTR. MS.ID.005457.

\section{ABSTRACT}

Our communication presents results of comparison metabolic rate and respiratory quotient values were determined in birds by two methods: Haldane gas analyzer (closed flow respirometry system) and an open flow respirometry system. In more than 40 species of Passerine birds were measured respiratory quotient (RQ) and basal metabolic rate (BMR). The analysis shows that determinations metabolic rate and RQ obtained by Haldane apparatus and the data measurement RQ obtained by an open flow respirometry systems were identical. The relationship BMR to body weight to the power of 0.72 $(\mathrm{BMR} / \mathrm{m} 0.72)$ and $\mathrm{RQ}$ values determination by Haldane gas analyzer and an open flow respirometry system in passerine birds were identical. RQ in winter was lower than in summer. RQ weakly correlates with BMR levels. Our study shows the possibility of using data obtained from previous studies that have been cited by investigators for a long time.

Keywords: Respiratory Quotient; Indirect Calorimetry; Physiology of Metabolism; Haldane Gas Analyzer; Open Flow Respirometry System

\section{Introduction}

All living organisms are dependent on metabolism (biochemical resource use and transformation) to fuel various vital activities. Metabolic rate, and the ratio of oxidizable substrates, which shows respiratory coefficient developed in parallel, reflecting life history and are basic characteristic traits of animals [1]. The study of the respiratory quotient in energetic is of particular interest and importance. RQ is an indicator of which fuel (carbohydrate or fat) is being metabolized to supply the body with energy. The main goal our study is to show how the Haldane method and closed flow respirometry system meets the modern requirements. Our data largely agree with results reported by other authors who used drastically different methods over several decades. This allows used past studies in current time. During the oxidation of various substrates, different amounts of $\mathrm{CO}_{2}$ are released. The ratio between $\mathrm{CO}_{2}$, which forms during the process of metabolism, and $\mathrm{O}_{2}$, which is consumed, is defined as the respiratory quotient (RQ). This parameter plays a major role in the physiology of metabolism $[2,3]$.

To accurately estimate the metabolic costs of animals under different conditions and feeding, it is necessary to measure $\mathrm{O}_{2}$ consumption and $\mathrm{CO}_{2}$ release simultaneously. Many methods to measure RQ were established over a century ago by [4] and are reiterated in detail in $[1,5,6]$. The following publications contain information on similar issues and to the measurement of energy metabolism in endothermic animals the papers by [6-14]. Transformation oxygen consumption in the energy value depends on RQ. Reliable measurements, equivalent units must be used for the oxygen and carbon dioxide levels. Otherwise, the ratio will be skewed and will be less meaningful as a result $[15,16]$. It is possible to pick up very accurate readings which can be used in respiratory quotient calculations. The question arises how the data obtained by different methods relate to each other. We compared the data measurements metabolic rate and RQ obtained by Haldane apparatus and the data measurement RQ obtained by an open flow respirometry systems.

\section{Methods}

The study was performed in Moscow Region at Zvenigorod Biological Station $\left(55^{\circ} 44^{\prime} \mathrm{N}, 36^{\circ} 51^{\prime} \mathrm{E}\right.$ ); more than 40 species of Passerine birds were used. The following indicators of energy 
metabolism were measured: The basal metabolic rate (BMR) in birds is the fundamental scale of its energetic power and an indicator of the maximal level of the daily work output. We used the relationship $\mathrm{BMR} / \mathrm{m}^{0.72}$ is an interspecies indicator of daily work output and may be applicable to general physiology and population ecology [14]. The respiratory quotient (RQ) is a dimensionless ratio of carbon dioxide produced by the body to oxygen consumed by the body. Measurement of metabolic rate and RQ were made in winter (December, January) and summer (end of May, June) on nonmounting birds. Studies made on seasonal variations of metabolic rate and RQ were done at experimentally controlled temperatures, where $\mathrm{T}_{\mathrm{A}}$ was varied from $+40^{\circ}$ to $-28^{\circ} \mathrm{C}$.

All experimental procedures and measurement methods are described in detail in our work [17]. Calculations and statistical processing of the results were performed using analysis of variance ANOVA. All data are expressed as the means \pm SE. The differences in the present study were estimated, and significance was determined using the t-test, as appropriate. The following statistics-associated abbreviations were used in this manuscript: $n$, sample size; p, statistical significance; t-test for independent samples, SE, standard error. The study was performed by the laws of the Russian Federation and Moscow State University regarding the capturing and holding of wild animals, and all individuals were released after the experiment. The average volume of consumed oxygen from the whole time of metabolic rate measurement was converted into the volume at standard temperature and pressure and then converted to $\mathrm{kJ}$ day according to the equation $1 \mathrm{~L}$ of $02=15.97+5.16 \mathrm{RQ}(\mathrm{kJ})$ $[8,18]$ and used as an estimate of whole-organism metabolic rate.

\section{Results}

All the results of measurements of metabolic rate and RQ in both winter and summer are summarized in Tables $1 \& 2$. The relationship BMR $/ \mathrm{m}^{0.72}$ obtained by the respirometry Fox Box of Sable Systems Inc is $2.9 \pm 0.42(n=108)$ and $2.76 \pm 0.35(n=216)$ obtained by the Haldane respirometry (Table 1). The respiratory coefficient in all birds at night is lower than in the daytime. The minimal values of the respiratory coefficient birds have at middle night (Table 1). Not found any difference in determining the RQ these two methods RQ values in 12 of passerine species obtained by the Haldane respirometry at night was in the range 0.71-0.83 and on average equal to $0.763 \pm 0.03(n=108)$. RQ values in the same species obtained by the respirometry FoxBox of Sable Systems Inc at night was in the range $0.72-0.80$ and on average equal to $0.760 \pm 0.02(n=216)$. There is a tendency for an increase in RQ in larger birds $\left(\mathrm{R}^{2}=0,1407\right), \mathrm{RQ}$ correlates with BMR levels: $\mathrm{RQ}=$ $-0,0482 B M R+0,842\left(R^{2}=0,3141\right)$.

Table 1: Results of comparison the relationship BMR $/ \mathrm{m}^{0.72}$ and $\mathrm{RQ}$ values determination by Haldane gas analyzer $\left(\mathrm{RQ}^{1}\right)$ and an open flow respirometry system $\left(\mathrm{RQ}^{2}\right)$ in birds.

\begin{tabular}{|c|c|c|c|c|c|c|c|}
\hline Species & Body mass & $\mathbf{n}$ & $\mathbf{R Q}$ & $\mathbf{B M R} / \mathbf{~ m}^{\mathbf{0}, 72} \mathbf{k J} / \mathbf{D}^{\mathbf{1}}$ & $\mathbf{n}$ & $\mathbf{R Q}^{\mathbf{2}}$ & $\mathbf{B M R}_{\mathbf{~}}^{\mathbf{0}, 72} \mathbf{k J} / \mathbf{D}^{\mathbf{2}}$ \\
\hline Carpodacus erythrinus & 21.2 & 1 & 0.712 & $3.53 \pm 0.14$ & 14 & $0.78 \pm 0.017$ & $3.2 \pm 0.38$ \\
\hline Chloris chloris & 28.2 & 11 & $0.787 \pm 0.019$ & $3.69 \pm 0.22$ & 17 & $0.794 \pm 0.021$ & $3.36 \pm 0.27$ \\
\hline Emberiza citrinella & 26.8 & 3 & $0.774 \pm 0.033$ & $3.06 \pm 0.28$ & 27 & $0.73 \pm 0.013$ & $2.38 \pm 0.14$ \\
\hline Erithacus rubecula & 17.6 & 25 & $0.761 \pm 0.04$ & $2.45 \pm 0.32$ & 18 & $0.781 \pm 0.016$ & $2.36 \pm 0.39$ \\
\hline Fringilla coelebs & 21 & 9 & $0.78 \pm 0.035$ & $2.68 \pm 0.19$ & 35 & $0.785 \pm 0.011$ & $2.74 \pm 0.49$ \\
\hline Loxia curvirostra & 39.4 & 1 & 0.781 & 3.18 & 9 & $0.744 \pm 0.028$ & $3.11 \pm 0.33$ \\
\hline Parus ater & 10.8 & 10 & $0.72 \pm 0.024$ & $2.5 \pm 0.25$ & 18 & $0.754 \pm 0.017$ & $2.31 \pm 0.32$ \\
\hline Parus major & 16.4 & 31 & $0.79 \pm 0.044$ & $2.67 \pm 0.27$ & 20 & $0.722 \pm 0.019$ & $2.71 \pm 0.49$ \\
\hline Spinus spinus & 14 & 3 & $0.736 \pm 0.036$ & $2.73 \pm 0.38$ & 18 & $0.761 \pm 0.023$ & $2.65 \pm 0.26$ \\
\hline Troglodytes troglodytes & 9 & 4 & $0.746 \pm 0.007$ & $2.44 \pm 0.21$ & 16 & $0.757 \pm 0.016$ & $2.41 \pm 0.59$ \\
\hline Turdus merula & 82.6 & 4 & $0.750 \pm 0.021$ & $3.01 \pm 0.17$ & 12 & $0.761 \pm 0.024$ & $2.97 \pm 0.22$ \\
\hline Turdus philomelos & 62.8 & 6 & $0.825 \pm 0.036$ & $2.84 \pm 0.26$ & 12 & $0.753 \pm 0.029$ & $2.86 \pm 0.18$ \\
\hline
\end{tabular}

Table 2: Summer and winter determination the relationship BMR $/ \mathrm{m}^{0.72}$ and $R Q$ values by Haldane gas analyzer $\left(\mathrm{RQ}^{1}\right)$ and an open flow respirometry system $\left(R^{2}\right)$ in birds.

\begin{tabular}{|c|c|c|c|c|c|c|c|c|}
\hline Species & Method & Body mass, $\mathrm{g}$ & $\mathbf{n}$ & RQ summer & $\begin{array}{l}\mathrm{BMR} / \mathrm{m}^{0,72} \mathrm{~kJ} / \mathrm{D} \\
\text { summer }\end{array}$ & $\mathbf{n}$ & RQ winter & $\begin{array}{c}\mathrm{BMR} / \mathrm{m}^{0,72} \mathrm{~kJ} / \mathrm{D} \\
\text { winter }\end{array}$ \\
\hline Parus ater & 1 & $10.8 \pm 1$ & 18 & $0.754 \pm 0.019$ & $3.7 \pm 0.25$ & 18 & $0.74 \pm 0.033$ & $4.15 \pm 0.81$ \\
\hline Parus ater & 2 & $10.8 \pm 0.95$ & 18 & $0.72 \pm 0.024$ & $3.43 \pm 0.34$ & 10 & $0.713 \pm 0.069$ & $3.35 \pm 0.21$ \\
\hline Parus caeruleus & 2 & $12.5 \pm 1.1$ & 7 & $0.737 \pm 0.026$ & $2.14 \pm 0.18$ & 7 & $0.727 \pm 0.029$ & $1.90 \pm 0.2$ \\
\hline Parus major & 1 & $16.4 \pm 1.2$ & 20 & $0.772 \pm 0.028$ & $2.61 \pm 0.27$ & 20 & $0.76 \pm 0.029$ & $2.82 \pm 0.32$ \\
\hline Parus major & 2 & $18.9 \pm 1.12$ & 31 & $0.79 \pm 0.044$ & $2.75 \pm 0.31$ & 12 & $0.781 \pm 0.024$ & $2.61 \pm 0.22$ \\
\hline Parus montanus & 2 & $11.6 \pm 0.9$ & 10 & $0.745 \pm 0.043$ & $2.29 \pm 0.31$ & 8 & $0.749 \pm 0.015$ & $2.22 \pm 0.16$ \\
\hline Sitta europaea & 2 & $22.9 \pm 1.45$ & 19 & $0.767 \pm 0.032$ & $2.29 \pm 0.26$ & 15 & $0.795 \pm 0.023$ & $2.46 \pm 0.22$ \\
\hline
\end{tabular}


We compared metabolic rate and RQ in summer and winter for some species (Table 2). There are practically no seasonal differences in the relationship BMR $/ \mathrm{m}^{0.72} 2.75 \pm 0.6 \mathrm{n}=123$ in summer $2.79 \pm 0.75$ $\mathrm{n}=90$ in winter to either in the RQ or between the two methods. The relationship BMR $/ \mathrm{m}^{0.72}$ and $\mathrm{RQ}$ is $0.755 \pm 0.02 \mathrm{n}=123$ in summer and $0.752 \pm 0.03 n=90$ in winter. These data indicate that lipids were the main source of energy expenditure in winter during a night. Thus, the RQ value and the metabolic rate determined using different methods were nearly identical. RQ values in 4 species of passerine birds which for many generations bred in captivity is $0.77 \pm 0.01$ (obtained by Haldane apparatus).

\section{Discussion}

This communication was designed to evaluate the interdependence of metabolic rate and RQ of birds and comparison results of these indicators obtained Haldane gas analyzer (closed flow respirometry system) and an open flow respirometry system. What is the significance of basal metabolic rate (BMR)? BMR is a measure of the minimum cost of organism maintenance, reflecting those basic physiological costs that are essential for life. The level of BMR among birds depends mainly on body mass, but after correcting for mass differences, there are still large differences among kinds of birds, especially between passerine birds and all other birds. In studied passerine birds RQ weakly correlates with BMR levels. The relationship BMR/m0.72, which reflects the ability of species to perform work, has no seasonal variations and is almost the same in all studied species. It is slightly higher than in non-passerine birds [14].

Benadé et al. [2] were carried out experiments, in which oxygen content, carbon dioxide content and RQ's obtained on expired air samples by the Haldane technique, were compared with those obtained using paramagnetic and infrared analysis. No significant bias was found between Haldane and paramagnetic analysis of oxygen content. The infrared analysis yielded more consistent results for $\mathrm{CO}_{2}$ than did the Haldane apparatus. The analysis shows that determinations RQ obtained by Haldane apparatus and the data measurement RQ obtained by an open flow respirometry systems are in confidence intervals of all data from literature [5$7,13,16,18]$.

We consider the mathematical and technical issues in the measurementandinterpretation of open-circuitindirectcalorimetry in small animals [6]. Measurement $\dot{\mathrm{VO}}_{2}$ and $\dot{\mathrm{V}} \mathrm{CO}_{2}$ showed that close relationships exist between relation $\dot{\mathrm{VO}}_{2}$ and $\dot{\mathrm{V}} \mathrm{CO}_{2}$ and energy expenditure derived precise equations well described in [19]. Our data indicate that in birds lipids were the primary source of energy expenditure in winter during night. It is especially interesting that the results of ours RQ values mostly agree with those by other authors with drastically different methods over several decades. This conclusion itself is important and add the current study's data to the complete database. The lends further credence importance of past studies that have been cited by investigators for a long time.
The results of $\mathrm{RQ}$ values and the relationship $\mathrm{BMR} / \mathrm{m}^{0.72}$ mostly agree with those by other authors with drastically various methods over several decades. This is important, and so is the value of the addition of the current study's data to the complete database. This it lends further credence importance of past studies that have been cited by investigators for a long time. This allows used previous studies in current time.

\section{Conclusion}

The analysis shows that determinations metabolic rate and RQ obtained by Haldane apparatus and the data measurement RQ obtained by an open flow respirometry systems were identical. RQ of captivity birds and free-living birds were identical. RQ in winter was lower than in summer. Our study shows the possibility of using data obtained from previous studies that have been cited by investigators for a long time. Due to the pandemic Covid-19, the results of RQ measurements can be used in clinical practice for severe pulmonary disease, in which patients spend a significant amount of energy on respiratory effort. In these cases, increasing the proportion of fats in the diet, the respiratory quotient is diminished causing a relative decrease in the amount of $\mathrm{CO}_{2}$ produced. This reduces the respiratory burden to eliminate $\mathrm{CO}_{2}$, thereby reducing the amount of energy spent on respirations.

\section{References}

1. Schmidt-Nielsen K (1997) Animal physiology: adaptation and environment $5^{\text {th }}(E d n)$. New York: Cambridge University Press.

2. Benadé AJS, Steydom NB, van der Walt WH (1970) A comparison of physical and chemical methods for the determination of respiratory quotient. Int Z angew Physiol 28(3): 193-196.

3. Gavrilov VM (2015) The stoichiometric approach in determining total evaporative water loss and the relationship between evaporative and non-evaporative heat loss in two resting bird species: passerine and non-passerine. Avian research 6: 19.

4. Elia M, Livesey G (1992) Energy expenditure and fuel selection in biological systems: the theory and practice of calculations based on indirect calorimetry and tracer methods. World Rev Nutr Diet 70: 68131.

5. Weir J B (1949) New methods for calculating metabolic rate with special reference to protein metabolism. J Physiol (Lond.) 109(1-2): 1-9.

6. Gavrilov VM (1997) Energetics and Avian Behavior. Soviet Scientific Reviews Series, Section F: Physiology and General Biology. London (United Kingdom): Harwood 11.

7. Haldane JS (1912) Methods of Air Analysis. London: Griffin.

8. Even PC, Mokhtarian A, Pele A (1994) Practical aspects of indirect calorimetry in laboratory animals. Neurosci. Biobehav. Rev 18(3): 435477.

9. Kleiber M (1961) The Fire of Life: An Introduction to Animal Energetics. New York: Wiley.

10. Simonson DC, de Fronzo RA (1990) Indirect calorimetry-methodological and interpretative problems. Am. J. Physiol 258: E399-E412.

11. Even PC, Nadkarni NA (2012) Indirect calorimetry in laboratory mice and rats: principles, practical considerations, interpretation and perspectives. Am J Physiol Regul Integr Comp Physiol 303(5): R459-R476.

12. Speakman JR (2013) Measuring Energy Metabolism in the Mouse. Theoretical, Practical, and Analytical Considerations. Front Physiol 4: 34. 
13. Dolnik VR, Gavrilov VM (1979) Bioenergetics of molt in the chaffinch (Fringilla coelebs) Auk 96(4): 253-264.

14. Gavrilov VM (2014) Ecological and scaling analysis of the energy expenditure of rest, activity, flight, and evaporative water loss in Passeriformes and Non-Passeriformes in relation to seasonal migrations and to the occupation of boreal stations in high and moderate latitudes. Quarterly Review of Biology 89(2):25-69.

15. Tschoep MH, Speakman JR, Arch JRS, Auwerx J, Brüning JC, et al. (2012) A guide to analysis of mouse energy metabolism. Nat. Methods 9: 57-63.

16. Gavrilov VV, Veselovskaya EO, Gavrilov VM, Goretskaya MYa, Morgunova GV (2013) Diurnal Rhythms of Locomotor Activity, Changes in Body Mass and Fat Reserves, Standard Metabolic Rate, and Respiratory Quotient in the Free-Living Coal Tit (Parus ater) in the Autumn-Winter Period. Biology Bulletin 40(8): 678-683.

\section{ISSN: 2574-1241}

DOI: $10.26717 /$ BJSTR.2021.33.005457

Valery M Gavrilov. Biomed J Sci \& Tech Res

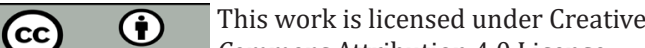

Submission Link: https://biomedres.us/submit-manuscript.php
17. Gavrilov VM, Gavrilov VV (2019) Scaling of total evaporative water loss and evaporative heat loss in birds at different ambient temperatures and seasons. International Journal of Avian \& Wildlife Biology 4(2): 40-47.

18. Even PC, Nadkarni NA (2012) Indirect calorimetry in laboratory mice and rats: principles, practical considerations, interpretation and perspectives. Am J Physiol Regul Integr Comp Physiol 303(5): R459-R476.

19. Kendeigh SC, Dolnik VR, Gavrilov VM (1977) Avian energetics. Granivorous Birds in Ecosystems: Their Evolution, Populations, Energetics, Adaptations, Impact and Control, Cambridge (United Kingdom): Cambridge University Press pp. 127-378. 